\title{
Physician Confidence in Artificial Intelligence: An Online Mobile Survey
}

Songhee $\mathrm{Oh}^{1}$, MD; Jae Heon $\mathrm{Kim}^{2}$, MD; Sung-Woo Choi ${ }^{3}$, MD; Hee Jeong Lee ${ }^{1}$, MD; Jungrak Hong ${ }^{4}$, MD; Soon Hyo Kwon ${ }^{1}$, MD

\footnotetext{
${ }^{1}$ Division of Nephrology, Department of Internal Medicine, Soonchunhyang University Hospital, Seoul, Republic of Korea

${ }^{2}$ Department of Urology, Soonchunhyang University Hospital, Seoul, Republic of Korea

${ }^{3}$ Department of Orthopedic Surgery, Soonchunhyang University Seoul Hospital, Seoul, Republic of Korea

${ }^{4}$ Department of Internal Medicine, New York Medical College, New York Health Hospital, New York, NY, United States
}

\section{Corresponding Author:}

Soon Hyo Kwon, MD

Division of Nephrology

Department of Internal Medicine

Soonchunhyang University Hospital

Daesagwanro 59 Youngsangu

Seoul, 04401

Republic of Korea

Phone: 8201034413147

Email: ksoonhyo@schmc.ac.kr

\section{Abstract}

Background: It is expected that artificial intelligence (AI) will be used extensively in the medical field in the future.

Objective: The purpose of this study is to investigate the awareness of AI among Korean doctors and to assess physicians' attitudes toward the medical application of AI.

Methods: We conducted an online survey composed of 11 closed-ended questions using Google Forms. The survey consisted of questions regarding the recognition of and attitudes toward AI, the development direction of AI in medicine, and the possible risks of using AI in the medical field.

Results: A total of 669 participants completed the survey. Only 40 (5.9\%) answered that they had good familiarity with AI. However, most participants considered AI useful in the medical field (558/669, 83.4\% agreement). The advantage of using AI was seen as the ability to analyze vast amounts of high-quality, clinically relevant data in real time. Respondents agreed that the area of medicine in which AI would be most useful is disease diagnosis $(558 / 669,83.4 \%$ agreement). One possible problem cited by the participants was that AI would not be able to assist in unexpected situations owing to inadequate information (196/669, $29.3 \%)$. Less than half of the participants $(294 / 669,43.9 \%)$ agreed that AI is diagnostically superior to human doctors. Only 237 $(35.4 \%)$ answered that they agreed that AI could replace them in their jobs.

Conclusions: This study suggests that Korean doctors and medical students have favorable attitudes toward AI in the medical field. The majority of physicians surveyed believed that AI will not replace their roles in the future.

(J Med Internet Res 2019;21(3):e12422) doi: 10.2196/12422

\section{KEYWORDS}

artificial intelligence; AI; awareness; physicians

\section{Introduction}

Research into and usage of artificial intelligence (AI) has been gaining popularity in the field of computer science [1-3]. Recently, various kinds of AI programs have been developed based on "big data" collected through the Internet of Things.
AI programs have been widely used in the manufacturing sector, the information-communications industry [4], and the medical field [5-7]. The development and utilization of AI programs in the medical field are currently entering the stage of commercialization [8,9]. AI is defined as the ability of computer systems to perform tasks that would usually require human levels of intelligence. A subfield of AI is machine learning, 
which can be used to teach a computer to analyze a vast amount of data in a rapid, accurate, and efficient manner through the use of complex computing and statistical algorithms [10,11].

In the past, it was thought that AI would replace doctors in many areas [12-15]. However, this has not occurred. Recent scientific advances have been rapid, suggesting that this might be a possibility. IBM's Watson was developed from a huge database of published literature and millions of medical records $[16,17]$. Based on this, it can assist in the establishment of precise diagnoses and proper treatment plans [16,17]. Furthermore, Watson provides advice on the best treatments for cancer and conducts genome analyses [18]. Similarly, Google's DeepMind software is being used to test the feasibility of the automated grading of digital fundus photographs using optical coherence tomography [19]. Recently, AI has been used to predict genetic variations in low-grade gliomas [20], identify genetic phenotypes in small cell lung carcinoma [21], decrease false-positive rates in screening mammography computer-aided detection [22], improve pathologic mediastinal lymph node detection [23], and automatically perform bone age assessment [24]. These examples demonstrate the influence of AI in medicine. The application of AI will be further extended to other areas in the future, leading to fundamental changes in the role of physicians and the way they practice medicine [25].

Korea is regarded as a technologically advanced country. Among people aged 18 to 24 years in the Republic of Korea, mobile phone penetration is $97.7 \%$. Of the approximately 19 million households in Korea, 99.2\% have internet access via an optical local area network, digital subscriber line (xDSL), cable modem, mobile device, or other media compared to approximately $75 \%$ in the United States [26].

There are differing perspectives on the future of AI. A pessimistic view of $\mathrm{AI}$ is that $\mathrm{AI}$ will replace humans in many industries. Optimistic views also exist in which humans will have more opportunities to benefit from clinical advances in the future with AI support [27]. Recently the AlphaGo AI program defeated a human Go professional, which shocked Korean society and provoked controversy in Korea [28,29].

Recent news reports revealed that Korean patients would follow AI advice over a doctor's advice about their cancer treatment [30]. However, there is no research on the opinions and attitudes of Korean physicians toward the application of AI programs in the medical field. Current medical students and young physicians will be affected by AI before they retire. Therefore, physicians need to be prepared for these changes to use AI effectively as a tool.

The purpose of this study is to investigate the awareness of AI programs among Korean medical doctors and to provide basic information about physicians' awareness of and reactions to the introduction of AI in the future.

\section{Methods}

\section{Participants}

This study was approved by an institutional review board at Soonchunhyang Medical College Hospital Seoul (no. 2017-05-014). Using Google Forms, we surveyed medical students, doctors who graduated from Soonchunhyang Medical College, and doctors at hospitals affiliated with Soonchunhyang University. The survey was administered online through a mobile phone invitation. Demographic and professional information on the medical students and doctors were obtained. Each participant was sent a unique link to the online survey. Participants were informed about the goal of the survey (medical research) in the preface of the questionnaire. By voluntarily participating in the survey after being given adequate information on its purpose, informed consent was implied. We confirm that participation was voluntary; participants could not be identified from the material presented and no plausible harm to participating individuals could arise from the study. Responses were made on a single Web page with one "submit" button that only allowed submissions through these unique links, thus making noninvited responses extremely unlikely.

\section{Measurement Instruments}

\section{Survey}

In May 2017, our online survey, consisting of 11 closed-ended questions, was conducted (Textbox 1 and Multimedia Appendix 1). Survey content validity was reviewed by study researchers $(n=5)$ and a panel of physicians $(n=5)$ who were accepting patients at their sites. Following this, pilot testing was performed by medical college students $(n=20)$ and physicians $(n=80)$ who did not participate in developing the survey. Our survey was in accordance with the Checklist for Reporting Results of Internet E-survey (CHERRIES) [31]. The contents of the survey consisted of a questionnaire regarding the recognition of and attitudes toward $\mathrm{AI}$, the direction of $\mathrm{AI}$ development in medicine, and the possible risks of using AI in the medical field. Three internal medicine physicians consulted the latest journals on $\mathrm{AI}$ and composed the questionnaire [5,6,9,16-18,32-34]. We sent 3000 doctors and medical students Web links to the questionnaire. These potential participants were almost entirely alumni of Soonchunhyang Medical College or were employed at hospitals affiliated with Soonchunhyang University.

The answers to five questions (Q1-Q5) were assessed using a five-point ordinal Likert scale (1=strongly disagree to $5=$ strongly agree). For three additional questions (Q6, Q8, Q10), 50 sample respondents were given to the questions in an open-ended format, and the five most commonly given answers were selected to be the five possible answer choices for survey participants. 
Textbox 1. Questions asked in the online survey regarding artificial intelligence (AI) in the medical field. The answers to questions $1-5$ were assessed with a five-point Likert scale ( $1=$ strongly disagree to $5=$ strongly agree).

\section{Attitudes}

Q1. Do you agree that you have good familiarity with artificial intelligence?

Q2. Do you agree that artificial intelligence has useful applications in the medical field?

Q3. Do you agree that the diagnostic ability of AI is superior to the clinical experience of a human doctor?

Q4. Do you agree that artificial intelligence could replace your job?

Q5. Do you agree that you would always use AI when making medical decisions in the future?

Q6. What are the advantages of using artificial intelligence?

- $\quad$ AI can speed up processes in health care

- $\quad$ AI can help reduce medical errors.

- $\quad$ AI can deliver vast amounts of clinically relevant high-quality data in real time

- $\quad$ AI has no space-time constraint

- AI has no emotional exhaustion nor physical limitation

Q7. If your medical judgment and an artificial intelligence's judgments differ, which will you follow?

- Doctor's opinion

- Artificial intelligence's opinion

- $\quad$ Patients' choice

\section{Expected Applications in Medicine}

Q8. In which field of medicine do you think artificial intelligence will be most useful?

- $\quad$ Making a diagnosis

- Making treatment decisions

- $\quad$ Direct treatment (including surgery)

- Biopharmaceutical research and development

- $\quad$ Providing medical assistance in underserved areas

- Development of social insurance program

Q9. Which sector of health care do you think will be the first to commercialize artificial intelligence?

- $\quad$ Public primary care such as public health centers

- $\quad$ Primary care in private clinics

- $\quad$ Specialized clinics (spine, knee, obstetrics and gynecology, etc)

- University hospitals

\section{Possible Risks}

Q10. What are you concerned about application of AI in medicine? It cannot be used to provide opinions in unpredicted situations due to inadequate

- Information

- It is not flexible enough to be applied to every patient

- It is difficult to apply to controversial subjects

- The low ability to sympathize and consider the emotional well-being of the patient

- It is developed by a specialist with little clinical experience in medical practice

Q11. Who do you think will be liable for legal problems caused by artificial intelligence?

- Doctor in charge

- Company that created the artificial intelligence

- $\quad$ Patient who consented to follow artificial intelligence's input 


\section{Questionnaire}

1. Attitudes: the first part of the survey asked about the physician's attitude toward the medical application of AI. The questions and possible answer choices (if applicable) are detailed in Multimedia Appendix 1. A total of seven closed-ended questions were included (Q1-Q7).

2. Expected applications in medicine: medical students and physicians were asked about the medical fields in which AI could be applied. The questions and possible answer choices are detailed in Multimedia Appendix 1. A total of two closed-ended questions were included (Q8 and Q9).

3. Possible risks: medical students and physicians were asked which problems they were concerned about regarding the application of AI in medicine. It is not clear who is liable when there are adverse clinical outcomes between humans and AI; therefore, we included a question about liability for AI decisions in medicine. The questions and possible answer choices for each question are detailed in Multimedia Appendix 1. A total of two closed-ended questions were included (Q10 and Q11).

\section{Subgroup Analyses: Specialty, Working Status, and Medical Experience}

We investigated whether attitudes differed regarding the medical applications of AI depending on the respondent's specialty degree of medical experience, working status, and work location.

For this study, the categories for department were medical student, physician, surgeon, or other. The categories for working status were medical student, training physician (intern, resident, or clinical fellow), university professor, or nonuniversity physician. The categories for amount of medical experience were the number of years licensed from medical school graduation: less than 10 years, between 10 and 20 years, or more than 20 years. The categories for working location were in and around Seoul, large cities outside of Seoul, small cities outside of Seoul, or small towns or rural areas.

\section{Statistical Analysis}

Basic statistics (mean and standard deviation or total number and percent) were computed for all covariates. In the subgroup analysis, Kruskal-Wallis tests served for evaluating the effect of gender factors of questionnaire items. The differences in the questionnaire responses according to working state, location, licensed years, and medical specialty were analyzed using the Mann-Whitney test. For all tests, the level of significance was set at $P \leq .05$.

\section{Results}

\section{Participants}

During the study period, 669 participants, out of approximately 3000 , completed the survey (22.3\% rate of return). There were 121 medical students, 162 training physicians, and 386 physicians. Among these participants, 22.4\% (150/669) were younger than 30 years, and $22.1 \%$ (148/669) were female. The demographic and professional characteristics of the participants are listed in Table 1.

\section{Questionnaire}

The results of the questionnaire are summarized in Table 2.

\section{Responses to the Questionnaire}

\section{Attitudes}

Generally, familiarity with AI was low. Only 40 of 669 respondents $(6.0 \%)$ answered that they had good familiarity with AI (Figure 1). Many participants considered AI useful in the medical field $(73.4 \%, 558 / 669)$. The respondents agreed that the advantages of using AI were its ability to quickly obtain vast amounts of clinically relevant, high-quality data in real time $(62.3 \%, 417 / 669)$, speed up processes in health care $(19.1 \%, 128 / 669)$, and decrease the number of medical errors $(9.6 \%, 64 / 669)$ (Figure 1). However, fewer than half of the participants agreed that "AI is superior to a doctor's experience" (44\%, 294/669), "AI could replace a doctor" (35.4\%, 237/669), or "AI would be used whenever medical decisions need to be made" (42\%, 281/669) (Figures 1 and 2). If there were differences between an AI's decision and a doctor's opinion regarding a medical decision, 79\% (528/669) of participants would follow the doctor's opinion. The results from the attitudes section of the questionnaire are summarized in Table 2.

\section{Expected Application in Medicine}

Respondents felt the areas in medicine where AI would be most useful in the future were reaching a diagnosis $(83.4 \%, 558 / 669)$ and forming a treatment plan $(53.8 \%, 360 / 669)$. Fewer than $10 \%$ felt it would be useful in providing medical assistance in underserved areas $(9.6 \%, 64 / 669)$, treating patients independently (eg, performing surgery, 9.0\%, 60/669), or developing medical insurance guidelines $(6.1 \%, 41 / 669)$. Additionally, most participants $(66.2 \%, 443 / 669)$ thought that AI would be first commercialized at a university hospital. The results from the expected fields section of the questionnaire are summarized in Table 2.

\section{Possible Risks}

According to the respondents, the possible problems with AI are that AI would be unable to provide an opinion in an unpredicted situation owing to inadequate information $(29.3 \%$, $196 / 669)$ and that it would not be applied to every patient $(34.1 \%, 228 / 669)$. In the case of a medical problem caused by $\mathrm{AI}$, respondents felt responsibility should lie with the doctors $(49.3 \%, 330 / 669)$, patients who consented to the use of AI $(31.2 \%, 209 / 669)$, and the company that created the AI (19.4\%, 130/669). The results from the possible risks section of the questionnaire are summarized in Table 2.

\section{Subgroup Analysis}

The results of subgroup analysis according to the demographic characteristics of participants are summarized in Table 3. 
Table 1. Demographic characteristics of participants surveyed about physicians and artificial intelligence $(\mathrm{N}=669)$.

\begin{tabular}{|c|c|}
\hline Characteristics & $\mathrm{n}(\%)$ \\
\hline \multicolumn{2}{|l|}{ Age (years) } \\
\hline$<30$ & $150(22.4)$ \\
\hline $31-40$ & $197(29.4)$ \\
\hline $41-50$ & $159(23.8)$ \\
\hline $51-60$ & $137(20.5)$ \\
\hline $61-70$ & $18(2.7)$ \\
\hline$\geq 71$ & $8(1.2)$ \\
\hline \multicolumn{2}{|l|}{ Gender } \\
\hline Male & $514(76.8)$ \\
\hline Female & $148(22.1)$ \\
\hline No response & $7(1.0)$ \\
\hline \multicolumn{2}{|l|}{ Working status } \\
\hline Medical student & $121(18.1)$ \\
\hline Training physicians (intern, residents, fellows) & $112(16.7)$ \\
\hline University professors & $90(13.5)$ \\
\hline Nonuniversity physicians & $346(51.7)$ \\
\hline \multicolumn{2}{|l|}{ Licensed years } \\
\hline Medical student & $121(18.1)$ \\
\hline$<10$ years & $177(26.5)$ \\
\hline $10-20$ years & $170(25.4)$ \\
\hline$>40$ years & $201(30.0)$ \\
\hline \multicolumn{2}{|l|}{ Medical specialty } \\
\hline Medical student & $121(18.1)$ \\
\hline Medical department & $284(42.5)$ \\
\hline Surgical department & $204(30.5)$ \\
\hline Extra department & $60(9.0)$ \\
\hline \multicolumn{2}{|l|}{ Hospital status } \\
\hline Medical school & $121(18.1)$ \\
\hline University hospital & $162(24.2)$ \\
\hline District general hospital & $67(10.0)$ \\
\hline Solo practice & $217(32.4)$ \\
\hline Group practice & $30(4.5)$ \\
\hline Long-term care hospital & $24(3.6)$ \\
\hline Community health center or military hospital & $29(4.3)$ \\
\hline Others & $19(2.8)$ \\
\hline \multicolumn{2}{|l|}{ Location of the clinics } \\
\hline Seoul (Capital city) & $278(41.6)$ \\
\hline Seoul Metropolitan Area (Capital area) & $162(24.2)$ \\
\hline Regional Metropolitan City & $44(6.6)$ \\
\hline Cities & $128(19.1)$ \\
\hline Rural & $57(8.5)$ \\
\hline
\end{tabular}


Table 2. Participant's attitudes on artificial intelligence (AI), the expected applications in medicine, and possible risks (N=669).

\begin{tabular}{ll}
\hline Question & $\mathrm{n}(\%)$ \\
\hline Attitudes & \\
Q1. Do you agree that you have good familiarity with artificial intelligence? & $40(6.0)$ \\
Strongly agree/agree & $320(47.8)$ \\
Neither disagree nor agree & $309(46.2)$ \\
Strongly disagree/disagree & \\
Q2. Do you agree that AI has useful applications in the medical field? & $558(73.4)$ \\
Strongly agree/agree & $97(14.5)$ \\
Neither disagree nor agree & $14(2.1)$ \\
Strongly disagree/disagree & \\
Q3. Do you agree that the diagnostic ability of AI is superior to the clinical experience of human doctors? & $294(44.0)$ \\
Strongly agree/agree & 206 (30.8) \\
Neither disagree nor agree & $169(25.2)$ \\
Strongly disagree/disagree
\end{tabular}

Q4. Do you agree that AI could replace you in your job?

Strongly agree/agree

Neither disagree nor agree

Strongly disagree/disagree

Q5. Do you agree that you will always use AI to make medical judgments in the future?

Strongly agree/agree (=always/often)

Neither disagree nor agree (=occasionally)

Strongly disagree/disagree (=never/seldom)

Q6. What are the advantages of using AI?

$\mathrm{AI}$ can speed up the process in health care

AI can help in reducing the number of medical errors

AI can deliver clinically relevant, vast amounts of high-quality data in real time

AI has no space-time constraint

AI has no emotional exhaustion or physical limitation

Q7. If your judgment and AI judgments differ, which will you follow?

Doctor's opinion

Artificial intelligence's opinion

Patients' choice

\section{Expected fields}

Q8. In which field of medicine do you think AI will be most useful?

Making diagnoses

Making the decision for treatment

Direct treatment (including surgery)

Biopharmaceutical research and development

Provide medical assistance in underserved areas

Development of social insurance program

Q9. Which sector of health care do you think will be the first to commercialize AI?

Public primary care such as public health centers 


\begin{tabular}{l}
\hline Question \\
\hline Specialized clinics (spine, knee, obstetrics, and gynecology, etc) \\
University hospitals \\
Possible risks \\
Q10. Which problems are you concerned about regarding the application of AI in medicine? \\
It cannot be used to provide opinions in unexpected situations owing to inadequate stored information \\
It is not flexible enough to be applied to every patient \\
It is difficult to apply to controversial subjects \\
Low ability to sympathize and consider the emotional well-being of the patient \\
It was developed by a specialist with little clinical experience in medical practice \\
Q11. Who do you think will be responsible for medical problems caused by AI? \\
Doctor in charge \\
Company that created the artificial intelligence \\
Patients who agreed to follow artificial intelligence's input \\
\hline
\end{tabular}

Figure 1. Major results of the questionnaire. AI: artificial intelligence.

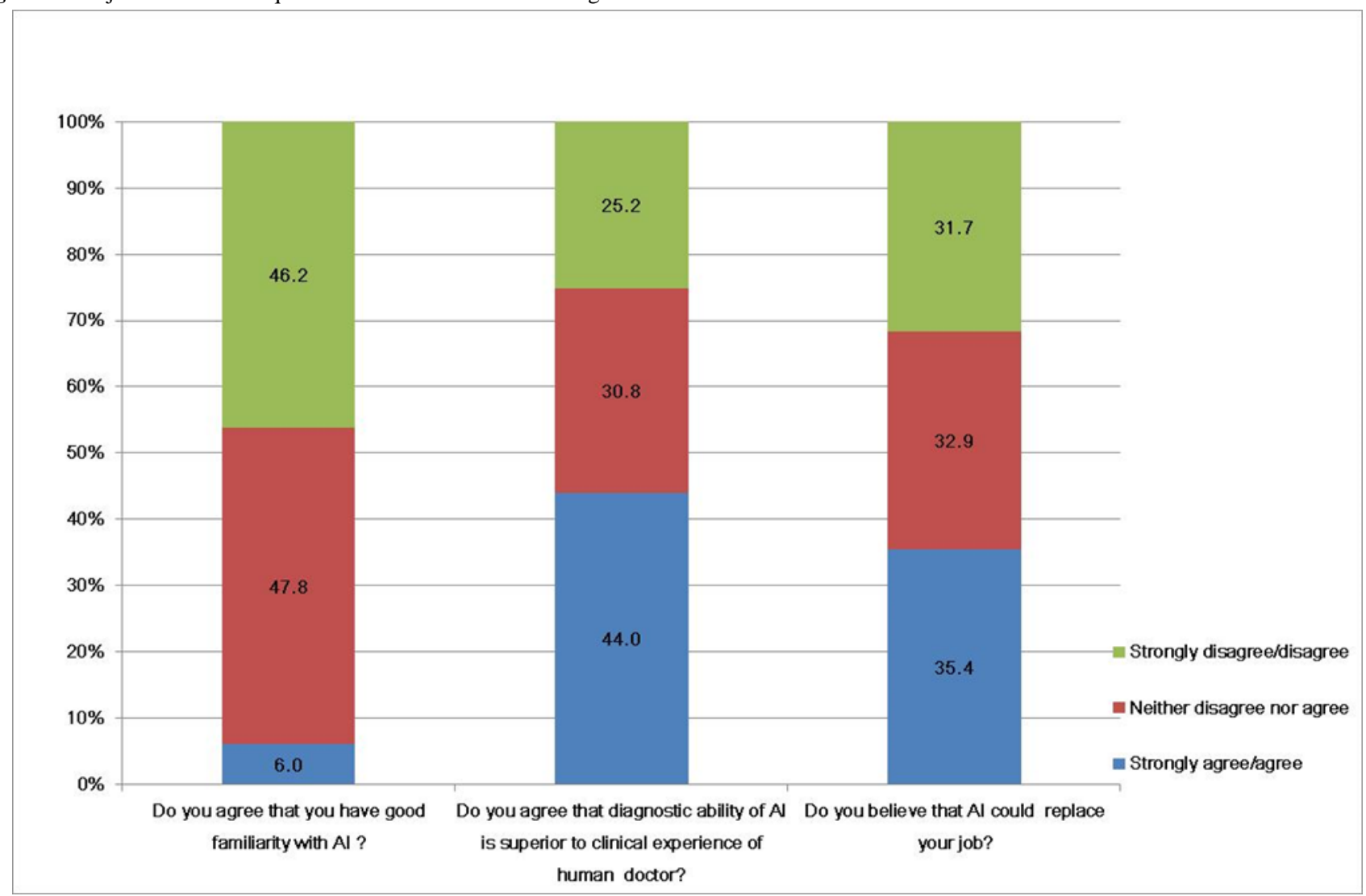

\section{Specialty}

There was no significant difference in attitude toward AI according to the department of the respondent for any of the questions (Q1-Q5).

\section{Working Status}

There were no significant differences according to working status for three questions (Q2, Q4, Q5). There were significant differences for two questions (Q1, Q3). For the question about the recognition of $\mathrm{AI}(\mathrm{Q} 1)$, the outcomes for training physicians are summarized in Table 4.

\section{Amount of Medical Experience}

There was no statistical difference according to the degree of medical experience for three questions (Q2, Q4, Q5). There were significant differences between two questions (Q1, Q3). For the question about the recognition of $\mathrm{AI}(\mathrm{Q} 1)$, the outcomes for physicians licensed for less than than 10 years, physicians licensed between 10 and 20 years, and physicians licensed more than 20 years were higher than for medical students. For the 
question about the superiority of AI in diagnostic ability (Q3), the outcomes of medical students and physicians licensed for fewer than 10 years were higher than for physicians licensed between 10 and 20 years and physicians licensed more than 20 years. The results of the subgroup analysis according to the amount of medical experience and age are summarized in Table
4. Age showed a similar result as the analysis according to license year.

\section{Working Location}

There was no significant difference in attitudes toward AI according to working location.

Figure 2. Responses about the advantage of artificial intelligence (AI) in medicine.

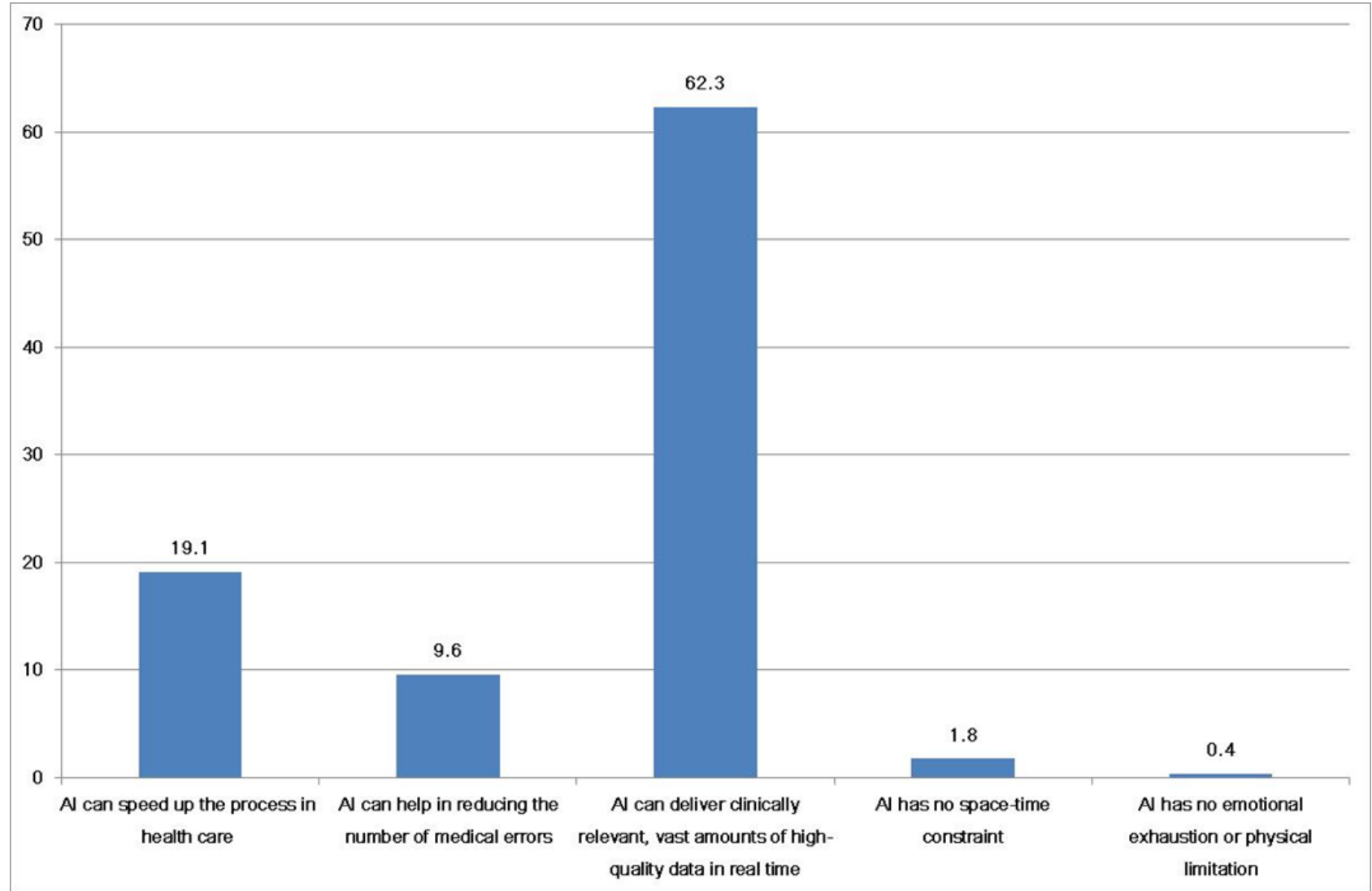

Table 3. Subgroup analysis according to the demographic characteristics of participants.

\begin{tabular}{llllll}
\hline Question & $\begin{array}{l}P \text { value }^{\mathrm{a}} \\
\text { Department }\end{array}$ & Working status & License year & Age & \multicolumn{1}{c}{ Location } \\
\hline Q1. Familiarity of AI & .06 & $<.001$ & $<.001$ & .001 & .54 \\
Q2. Usefulness of AI & .07 & .11 & .24 & $<.001$ & .001 \\
Q3. Diagnostic ability of AI & .38 & .001 & .35 & .32 & .07 \\
Q4. Replacement human job (doctor) & .46 & .19 & .92 & .43 & .52 \\
Q5. Frequency of using AI & .92 & .95 & .17 \\
\hline
\end{tabular}

${ }^{\mathrm{a}} P$ values for categorical variables are based on Kruskal-Wallis tests.

${ }^{\mathrm{b}} \mathrm{AI}$ : artificial intelligence. 
Table 4. Subgroup analysis according to working status.

\begin{tabular}{|c|c|c|c|}
\hline Subgroup and question & Median $\left(\mathrm{IQR}^{\mathrm{a}}\right)$ & $P$ value $^{\mathrm{b}}$ & Post hoc \\
\hline \multicolumn{4}{|l|}{ Working status } \\
\hline Q1. Familiarity with $\mathrm{AI}^{\mathrm{c}}$ & & $<.001$ & $\mathrm{~A}<\mathrm{B}, \mathrm{C}, \mathrm{D}$ \\
\hline A. Students & $2(2-3)$ & & \\
\hline B. Training physician & $3(2-3)$ & & \\
\hline C. Professor & $3(2-3)$ & & \\
\hline D. Clinical physicians & $3(2-3)$ & & \\
\hline Q3. Diagnostic ability of AI & & .001 & $\mathrm{~A}=\mathrm{B}>\mathrm{C}=\mathrm{D}$ \\
\hline A. Students & $4(3-4)$ & & \\
\hline B. Training physician & $4(3-4)$ & & \\
\hline C. Professor & $3(2-3)$ & & \\
\hline D. Clinical physicians & $3(2-4)$ & & \\
\hline \multicolumn{4}{|l|}{ License year } \\
\hline Q1. Familiarity with AI & & $<.001$ & $\mathrm{~A}<\mathrm{B}=\mathrm{C}=\mathrm{D}$ \\
\hline A. Students & $2(2-3)$ & & \\
\hline B. $<10$ years & $3(2-3)$ & & \\
\hline C. $10-20$ years & $3(2-3)$ & & \\
\hline D. $>20$ years & $3(2-3)$ & & \\
\hline Q3. Diagnostic ability of AI & & $<.001$ & $\mathrm{~A}=\mathrm{B}>\mathrm{C}=\mathrm{D}$ \\
\hline A. Students & $4(3-4)$ & & \\
\hline B. $<10$ years & $4(3-4)$ & & \\
\hline C. $10-20$ years & $3(2-4)$ & & \\
\hline D. $>20$ years & $3(2-4)$ & & \\
\hline \multicolumn{4}{|l|}{ Age } \\
\hline Q1. Familiarity with AI & & $<.001$ & $\mathrm{~A}<\mathrm{B}=\mathrm{C}=\mathrm{D}=\mathrm{E}$ \\
\hline A. $20-29$ years & $2(2-3)$ & & \\
\hline B. $30-39$ years & $3(2-3)$ & & \\
\hline C. $40-49$ years & $3(2-3)$ & & \\
\hline D. $50-59$ years & $3(2-3)$ & & \\
\hline E. $>60$ years & $3(2-3)$ & & \\
\hline Q3. Diagnostic ability of AI & & $<.001$ & $\mathrm{~A}=\mathrm{B}>\mathrm{C}=\mathrm{D}=\mathrm{E}$ \\
\hline A. $20-29$ years & $3(3-4)$ & & \\
\hline B. $30-39$ years & $4(3-4)$ & & \\
\hline C. $40-49$ years & $3(2-4)$ & & \\
\hline D. 50-59 years & $3(2-4)$ & & \\
\hline E. $>60$ years & $3(2-4)$ & & \\
\hline
\end{tabular}

${ }^{\mathrm{a}} \mathrm{IQR}$ : interquartile range.

${ }^{\mathrm{b}} P$ values for categorical variables are based on Mann-Whitney tests.

${ }^{\mathrm{c}} \mathrm{AI}$ : artificial intelligence. 


\section{Discussion}

\section{Principal Results and Comparison With Prior Work}

To the best of our knowledge, this study is the first survey of the attitudes of physicians toward AI. The results of this survey suggest that the recognition of AI by medical students and doctors is low. However, they regarded AI to be useful in the medical field. Physicians and medical students felt that AI would be most useful for reaching a diagnosis and formulating a treatment in the future. The majority of Korean doctors do not believe that AI will replace them.

Precision medicine is "an emerging approach for disease treatment and prevention that takes into account individual variability in genes, environment, and lifestyle for each person" [35]. This approach allows doctors to choose treatment and prevention strategies for their patients. It requires significant computing power and algorithms that can learn by themselves at an unprecedented rate. Therefore, there is no precision medicine without AI. In our study, most physicians expected that AI would be helpful with diagnoses and in planning treatment by providing the latest clinically relevant data.

We asked the participants about the diagnostic superiority of AI compared to that of doctors. Fewer than half of the participants agreed that AI would be diagnostically superior. In the subgroup analysis, doctors in academic positions and office clinicians who had more clinical experience were less likely than medical students and training physicians to agree that AI is diagnostically superior. Additionally, experienced clinicians (licensed for more than 10 years) were less likely to agree that AI has superior diagnostic ability. Our questions were about general clinical practice. Although pathologists and radiologists were among the respondents, there were relatively few $(27 / 669$, $4.0 \%)$.

In contrast to our study, recent studies have shown that image recognition technology might make predictions or recognize diseases as effectively as or even better than physicians $[17,36]$. Liu and colleagues [36] from Google used an AI technique called convolutional neural network machine learning and demonstrated that $\mathrm{AI}$ achieves image-level area under the curve scores greater than $97 \%$ on both the Camelyon 16 test set (metastasis detection of lymph nodes) and an independent set of 110 slides compared to a human pathologist, who achieved $73.2 \%$ sensitivity. Metastasis detection is currently performed by pathologists when reviewing large expanses of biological tissue. This process is labor intensive and error prone. However, AI machine learning saves time and is less likely to make errors [37]. In the case of radiology and pathology, some believe that AI will replace doctors based on diagnostic superiority $[9,25,38]$. Furthermore, AI could be able to extract fine information about tissues invisible to the human eye and process these data quickly and accurately $[39,40]$.

Generally, AI has been used in imaging and pathology and is considered favorably in these fields [41-45]. Pathology and radiology have a common destiny as "informational specialists" with regard to images and pathology [38]. However, we did not investigate the reasons for their choices. They might believe that technical progress in the field of AI will not reach the level of human intelligence. It is also possible that Korean physicians have not examined the recent data on $\mathrm{AI}$ in the medical field.

In our study, $35.4 \%$ of participants agreed that doctors will be replaced by AI. This is not consistent with previous studies about AI. A 2017 survey by the Pew Research Center conducted with 4135 participants found that the public is roughly twice as likely to express worry (72\%) than enthusiasm (33\%) about a future in which robots and computers are capable of doing many human jobs [46]. Unlike other occupations, doctors felt that there would be difficulties in replacing doctors. Krittanawong [40] argued that AI cannot replace doctors yet at the bedside, given its limitations. First, AI cannot engage in high-level conversation with patients to gain their trust, reassure them, or express empathy [47]. These are all important parts of the doctor-patient relationship. Second, although AI sensors may glean valuable information to help with diagnosis, physicians will still be needed for interpretation in ambiguous situations to integrate medical histories, conduct physical exams, and facilitate further discussion [40]. It is possible that many Korean doctors believe this intuitively.

Skepticism can arise when applying AI to medical care. Regulations and principles of AI application need to be defined. AI can provoke ethical and legal problems in medicine. A regulatory authority should control AI algorithms for public safety. This issue will require debate from a social perspective.

Our survey response rate was $22.3 \%$, which seems to be a lower response rate. However, previous studies demonstrated that electronic modalities often have lower response rates than paper mailed surveys [48-50]. Internet-based surveys demonstrated a lower response rate $(45 \%)$ than the mail questionnaires $(58 \%)$ (absolute difference 13\%, 95\% confidence interval 4\%-22\%, $P<.01$ ) [48]. A Cochrane review of randomized controlled trials identified numerous methods to increase response rates for both postal and electronic surveys [51]. With reference to this study, we made the questionnaire short, used a simple header, and gave a deadline. However, there were no monetary incentives, one of the major factors that increase the response rate. Plus, we could not provide a prenotification nor send reminder messages or have follow-up contact because we could not distinguish between those who already responded and the nonresponders.

\section{Limitations}

Some limitations of our study should be noted. First, we did not ask background questions concerning how much the individual participants technically understood AI. Each participant may have had different conceptualizations of AI. Second, there is the possibility of selection bias. Participants may have been more motivated and might have expressed more positive attitudes compared to nonparticipants. Because the data were self-reported, a bias owing to social desirability cannot be excluded. In addition, the selected participants may not have been a good representation of Korean doctors in general. However, our study did include various ages and clinical backgrounds. Third, the questionnaire about AI was created by doctors rather than AI experts. 


\section{Conclusion}

This study found that physicians felt the application of AI to medicine would be useful. Physicians felt that the areas in medicine where AI would be most useful were diagnosis and treatment planning. However, more than half of the physicians did not believe AI would replace their role as health care providers. From a diagnostic point of view, doctors who had more experience favored a physician's experience over AI. Follow-up surveys and multinational studies should be conducted to further explore these issues.

\section{Acknowledgments}

This study was supported by a Soonchunhyang University research grant (20180005).

\section{Conflicts of Interest}

None declared.

\section{Multimedia Appendix 1}

Online survey form.

[PDF File (Adobe PDF File), 250KB-Multimedia Appendix 1]

\section{References}

1. Hastie TT, Friedman J, Tibshirani R. The Elements of Statistical Learning. New York: Springer Science \& Business Media; 2009.

2. Abu-Mostafa Y, Magdon-Ismail M, Lin HT. Learning from Data. Learning From Data: AMLbook.com; 2012.

3. Kononenko I. Machine learning for medical diagnosis: history, state of the art and perspective. Artif Intell Med 2001 Aug;23(1):89-109. [Medline: 11470218]

4. Pyo S, Lee J, Cha M, Jang H. Predictability of machine learning techniques to forecast the trends of market index prices: hypothesis testing for the Korean stock markets. PLoS One 2017 Nov;12(11):e0188107 [FREE Full text] [doi: 10.1371/journal.pone.0188107] [Medline: 29136004]

5. Miller DD, Brown EW. Artificial intelligence in medical practice: the question to the answer? Am J Med 2018 Feb;131(2):129-133. [doi: 10.1016/j.amjmed.2017.10.035] [Medline: 29126825]

6. Patel VL, Shortliffe EH, Stefanelli M, Szolovits P, Berthold MR, Bellazzi R, et al. The coming of age of artificial intelligence in medicine. Artif Intell Med 2009 May;46(1):5-17 [FREE Full text] [doi: 10.1016/j.artmed.2008.07.017] [Medline: 18790621]

7. Ohno-Machado L. Research on machine learning issues in biomedical informatics modeling. J Biomed Inform 2004 Aug;37(4):221-223 [FREE Full text] [doi: 10.1016/j.jbi.2004.07.004] [Medline: 15465475]

8. Nemati S, Holder A, Razmi F, Stanley MD, Clifford GD, Buchman TG. An interpretable machine learning model for accurate prediction of sepsis in the ICU. Crit Care Med 2018 Apr;46(4):547-553. [doi: 10.1097/CCM.0000000000002936] [Medline: 29286945]

9. Dreyer KJ, Geis JR. When machines think: radiology's next frontier. Radiology 2017 Dec;285(3):713-718. [doi: 10.1148/radiol.2017171183] [Medline: 29155639]

10. Alsharqi M, Woodward W, Mumith A, Markham D, Upton R, Leeson P. Artificial intelligence and echocardiography. Echo Res Pract 2018 Dec 05:30400053. [doi: 10.1530/ERP-18-0056] [Medline: 30400053]

11. Shameer K, Johnson KW, Glicksberg BS, Dudley JT, Sengupta PP. Machine learning in cardiovascular medicine: are we there yet? Heart 2018 Jan 19;104(14):1156-1164. [doi: 10.1136/heartjnl-2017-311198]

12. Lusted LB. Logical analysis in roentgen diagnosis. Radiology 1960 Feb;74:178-193. [doi: 10.1148/74.2.178] [Medline: 14419034]

13. Schwartz WB. Medicine and the computer. N Engl J Med 1970 Dec 03;283(23):1257-1264. [doi: 10.1056/nejm197012032832305]

14. Chockley K, Emanuel E. The end of radiology? Three threats to the future practice of radiology. J Am Coll Radiol 2016 Dec;13(12 Pt A):1415-1420. [doi: 10.1016/j.jacr.2016.07.010] [Medline: 27652572]

15. Jha S. Medscape. 2016 May 12. Will computer replace radiologist? URL: https://login.medscape.com/login/sso/ getlogin?urlCache=aHR0cHM6Ly93d3cubWVkc2NhcGUuY29tL3ZpZXdhcnRpY2xlLzg2MzEyNw==\&ac=401 $[$ accessed 2019-02-11] [WebCite Cache ID 766qprzqW]

16. Bakkar N, Kovalik T, Lorenzini I, Spangler S, Lacoste A, Sponaugle K, et al. Artificial intelligence in neurodegenerative disease research: use of IBM Watson to identify additional RNA-binding proteins altered in amyotrophic lateral sclerosis. Acta Neuropathol 2018 Feb;135(2):227-247 [FREE Full text] [doi: 10.1007/s00401-017-1785-8] [Medline: 29134320]

17. Trivedi H, Mesterhazy J, Laguna B, Vu T, Sohn JH. Automatic determination of the need for intravenous contrast in musculoskeletal MRI examinations using IBM Watson's natural language processing algorithm. J Digit Imaging 2018 Apr;31(2):245-251. [doi: 10.1007/s10278-017-0021-3] [Medline: 28924815] 
18. Malin JL. Envisioning Watson as a rapid-learning system for oncology. J Oncol Pract 2013 May;9(3):155-157 [FREE Full text] [doi: 10.1200/JOP.2013.001021] [Medline: 23942497]

19. De Fauw FJ, Keane P, Tomasev N, Visentin D, van den Driessche G, Johnson M, et al. Automated analysis of retinal imaging using machine learning techniques for computer vision. F1000Res 2016 Jun;5:1573 [FREE Full text] [doi: 10.12688/f1000research.8996.2] [Medline: 27830057]

20. Korfiatis P, Kline TL, Lachance DH, Parney IF, Buckner JC, Erickson BJ. Residual deep convolutional neural network predicts MGMT methylation status. J Digit Imaging 2017 Oct;30(5):622-628 [FREE Full text] [doi: 10.1007/s10278-017-0009-z] [Medline: 28785873]

21. Rios VE, Parmar C, Liu Y, Coroller TP, Cruz G, Stringfield O, et al. Somatic mutations drive distinct imaging phenotypes in lung cancer. Cancer Res 2017 Dec 15;77(14):3922-3930 [FREE Full text] [doi: 10.1158/0008-5472.CAN-17-0122] [Medline: 28566328]

22. Mordang J, Gubern-Mérida A, Bria A, Tortorella F, den Heeten HG, Karssemeijer N. Improving computer-aided detection assistance in breast cancer screening by removal of obviously false-positive findings. Med Phys 2017 Apr;44(4):1390-1401. [doi: 10.1002/mp.12152] [Medline: 28182277]

23. Liu J, Hoffman J, Zhao J, Yao J, Lu L, Kim L, et al. Mediastinal lymph node detection and station mapping on chest CT using spatial priors and random forest. Med Phys 2016 Jul;43(7):4362 [FREE Full text] [doi: 10.1118/1.4954009] [Medline: 27370151]

24. Lee H, Tajmir S, Lee J, Zissen M, Yeshiwas BA, Alkasab TK, et al. Fully automated deep learning system for bone age assessment. J Digit Imaging 2017 Aug;30(4):427-441 [FREE Full text] [doi: 10.1007/s10278-017-9955-8] [Medline: 28275919]

25. Diprose W, Buist N. Artificial intelligence in medicine: humans need not apply? N Z Med J 2016 May 06;129(1434):73-76. [Medline: 27349266]

26. Ramirez E. Forbes. 2017 Jan 31 . Nearly $100 \%$ of households in South Korea now have internet access, thanks to seniors URL: https://www.forbes.com/sites/elaineramirez/2017/01/31/

nearly-100-of-households-in-south-korea-now-have-internet-access-thanks-to-seniors/\#1c05a9c55572 [accessed 2019-02-06] [WebCite Cache ID 75yHsuhVW]

27. Johnston SC. Anticipating and training the physician of the future: the importance of caring in an age of artificial intelligence. Acad Med 2018 Aug;93(8):1105-1106. [doi: 10.1097/ACM.0000000000002175] [Medline: 29443717]

28. Metz C. Wired. 2016 Mar 11. The sadness and beauty of watching Google's AI play Go URL: https://www.wired.com/ 2016/03/sadness-beauty-watching-googles-ai-play-go/ [accessed 2019-02-06] [WebCite Cache ID 75yI9Hsj9]

29. Kim H. Lessons from the Lee Sedol vs AlphaGo match. Korea IT Times 2016 Mar 14:1.

30. Kim C. Chosun.com. Dr Watson and the medical staff...patient URL: http://news.chosun.com/site/data/html dir/2017/01/ 12/2017011200289.html [accessed 2019-02-06] [WebCite Cache ID 75yIZJ9WE]

31. Eysenbach G. Improving the quality of Web surveys: the Checklist for Reporting Results of Internet E-Surveys (CHERRIES). J Med Internet Res 2004 Dec 29;6(3):e34 [FREE Full text] [doi: 10.2196/jmir.6.3.e34] [Medline: 15471760]

32. Luxton DD. Recommendations for the ethical use and design of artificial intelligent care providers. Artif Intell Med 2014 Sep;62(1):1-10. [doi: 10.1016/j.artmed.2014.06.004] [Medline: 25059820]

33. Knight BA, Potretzke AM, Larson JA, Bhayani SB. Comparing expert reported outcomes to national surgical quality improvement program risk calculator-predicted outcomes: do reporting standards differ? J Endourol 2015 Sep;29(9):1091-1099. [doi: 10.1089/end.2015.0178] [Medline: 25936420]

34. Dawes T, de Marvao A, Shi W, Fletcher T, Watson G, Wharton J, et al. Machine learning of three-dimensional right ventricular motion enables outcome prediction in pulmonary hypertension: a cardiac MR imaging study. Radiology 2017 Dec;283(2):381-390 [FREE Full text] [doi: 10.1148/radiol.2016161315] [Medline: 28092203]

35. James R. National Institute of on Minority Health and Health Disparities. 2017. National Institutes of Health Precision medicine initiative URL: https://www.nimhd.nih.gov/about/legislative-info/clips/pmi.html [accessed 2019-02-05] [WebCite Cache ID 75yNuNGg5]

36. Liu Y, Gadepalli K, Norouzi M, Dahl G, Kohlberger T, Boyko A, et al. Detecting cancer metastases on gigapixel pathology images. arVix 2017:1703-02442v2 [FREE Full text]

37. Buch VH, Ahmed I, Maruthappu M. Artificial intelligence in medicine: current trends and future possibilities. Br J Gen Pract 2018 Mar;68(668):143-144. [doi: 10.3399/bjgp18X695213] [Medline: 29472224]

38. Jha S, Topol EJ. Adapting to artificial intelligence: radiologists and pathologists as information specialists. JAMA 2016 Dec 13;316(22):2353-2354. [doi: 10.1001/jama.2016.17438] [Medline: 27898975]

39. Kayser K, Görtler J, Bogovac M, Bogovac A, Goldmann T, Vollmer E, et al. AI (artificial intelligence) in histopathology--from image analysis to automated diagnosis. Folia Histochem Cytobiol 2009 Jan;47(3):355-361 [FREE Full text] [doi: 10.2478/v10042-009-0087-y] [Medline: 20164018]

40. Krittanawong C. The rise of artificial intelligence and the uncertain future for physicians. Eur J Intern Med 2018 Dec;48:e13-e14. [doi: 10.1016/j.ejim.2017.06.017] [Medline: 28651747]

41. Zhou S, Greenspan H, Shen D. Deep Learning for Medical Image Analysis. Cambridge: Elsevier; 2017. 
42. Gulshan V, Peng L, Coram M, Stumpe MC, Wu D, Narayanaswamy A, et al. Development and validation of a deep learning algorithm for detection of diabetic retinopathy in retinal fundus photographs. JAMA 2016 Dec 13;316(22):2402-2410. [doi: 10.1001/jama.2016.17216] [Medline: 27898976]

43. Esteva A, Kuprel B, Novoa RA, Ko J, Swetter SM, Blau HM, et al. Dermatologist-level classification of skin cancer with deep neural networks. Nature 2017 Jan 25;542(7639):115-118. [doi: 10.1038/nature21056]

44. Ehteshami BB, Veta M, Johannes VD, van Diest B, Karssemeijer N, Litjens G, the CAMELYON16 Consortium, et al. Diagnostic assessment of deep learning algorithms for detection of lymph node metastases in women with breast cancer. JAMA 2017 Dec 12;318(22):2199-2210 [FREE Full text] [doi: 10.1001/jama.2017.14585] [Medline: 29234806]

45. Yu K, Zhang C, Berry GJ, Altman RB, Ré C, Rubin DL, et al. Predicting non-small cell lung cancer prognosis by fully automated microscopic pathology image features. Nat Commun 2016 Dec 16;7:12474 [FREE Full text] [doi: 10.1038/ncomms12474] [Medline: 27527408]

46. Smith A, Anderson M. Pew Research Center. 2017 Oct 4. Automation in everyday life URL: http://www.pewinternet.org/ 2017/10/04/automation-in-everyday-life/ [accessed 2019-02-05] [WebCite Cache ID 75yShocGY]

47. Inkster B, Sarda S, Subramanian V. An empathy-driven, conversational artificial intelligence agent (Wysa) for digital mental well-being: real-world data evaluation mixed-methods study. JMIR Mhealth Uhealth 2018 Nov 23;6(11):e12106. [doi: $10.2196 / 12106]$

48. Leece P, Bhandari M, Sprague S, Swiontkowski MF, Schemitsch EH, Tornetta P, et al. Internet versus mailed questionnaires: a controlled comparison (2). J Med Internet Res 2004 Oct 29;6(4):e39. [doi: 10.2196/jmir.6.4.e39]

49. Crouch S, Robinson P, Pitts M. A comparison of general practitioner response rates to electronic and postal surveys in the setting of the National STI Prevention Program. Aust N Z J Public Health 2011 Apr;35(2):187-189. [doi: 10.1111/j.1753-6405.2011.00687.x] [Medline: 21463418]

50. VanGeest JB, Johnson TP, Welch VL. Methodologies for improving response rates in surveys of physicians: a systematic review. Eval Health Prof 2007 Dec;30(4):303-321. [doi: 10.1177/0163278707307899] [Medline: 17986667]

51. Edwards PJ, Roberts I, Clarke MJ, Diguiseppi C, Wentz R, Kwan I, et al. Methods to increase response to postal and electronic questionnaires. Cochrane Database Syst Rev 2009(3):MR000008. [doi: 10.1002/14651858.MR000008.pub4] [Medline: 19588449]

\section{Abbreviations \\ AI: artificial intelligence \\ IQR: interquartile range}

Edited by M Focsa; submitted 15.10.18; peer-reviewed by Y Liu, J Rey-Martinez, S Zheng; comments to author 03.12.18; revised version received 09.01.19; accepted 17.01.19; published 25.03.19

Please cite as:

Oh S, Kim JH, Choi SW, Lee HJ, Hong J, Kwon SH

Physician Confidence in Artificial Intelligence: An Online Mobile Survey

J Med Internet Res 2019;21(3):e12422

URL: http://www.jmir.org/2019/3/e12422/

doi: $10.2196 / 12422$

PMID: 30907742

(C) Songhee Oh, Jae Heon Kim, Sung-Woo Choi, Hee Jeong Lee, Jungrak Hong, Soon Hyo Kwon. Originally published in the Journal of Medical Internet Research (http://www.jmir.org), 25.03.2019. This is an open-access article distributed under the terms of the Creative Commons Attribution License (https://creativecommons.org/licenses/by/4.0/), which permits unrestricted use, distribution, and reproduction in any medium, provided the original work, first published in the Journal of Medical Internet Research, is properly cited. The complete bibliographic information, a link to the original publication on http://www.jmir.org/, as well as this copyright and license information must be included. 